\title{
Thermal-Swing Adsorption of Europium(III) with Poly( $N$-isopropylacrylamide) Combined with an Acidic Extractant
}

\author{
Syouhei NISHIHAMA, ${ }^{1,3 *}$ Satomi MATSUNAGA,${ }^{1}$ Seitaro TAKAYAMA, ${ }^{1}$ Tokie OOKUBO, ${ }^{1,3}$ \\ Kazuharu YOSHIZUKA, ${ }^{1,3}$ Tsuyohiko FUJIGAYA, ${ }^{2}$ and Naotoshi NAKASHIMA ${ }^{2,3}$ \\ 1 Department of Chemical Engineering, The University of Kitakyushu, Hibikino 1-1, \\ Kitakyushu 808-0135, Japan \\ 2 Department of Applied Chemistry, Graduate School of Engineering, Kyushu University, \\ 744 Motooka, Fukuoka 819-0395, Japan \\ 3 JST-CREST, 5 Sanbancho, Chiyoda, Tokyo 102-0075, Japan
}

(Received August 1, 2013; Accepted October 16, 2013)

\begin{abstract}
A thermal-swing adsorption system for $\mathrm{Eu}(\mathrm{III})$ was developed using the thermosensitive polymer, poly( $N$-isopropylacrylamide) (PNIPAM), combined with the acidic extractants, acid phosphoxy ethyl methacrylate (Phosmer-M) or acrylic acid. The phase transition of the PNIPAM/acidic extractant copolymers was successfully achieved by changing the temperature around the lower critical solution temperature (LCST). The thermal-swing adsorption of Eu(III) was correspondingly achieved by changing the temperature of the aqueous solution. The adsorption ability of $\mathrm{Eu}(\mathrm{III})$ was increased when the temperature became higher than the LCST, due to the change in the hydrophobicity as well as in the volume of the copolymer. The difference in the adsorption at lower and higher temperatures against the LCST was increased with decreasing crosslinking agent during the preparation of the copolymer. The copolymer possessed sufficient loading and release capacity for Eu(III) even in repeated processes of the thermal-swing adsorption.
\end{abstract}

\section{Introduction}

Integration of solvent extraction systems with solid-liquid processes has been widely investigated as second-generation extraction materials for the separation of metal ions, since solvent extraction systems require a large amount of organic solvent to dissolve both extractant and extracted species. Besides, improvement of the solid-liquid systems is required to decrease the amount of acid for stripping the extracted metals. In particular, the amount of acid waste in the nuclear fuel cycle process must be reduced, since secondary waste containing radioactive elements is generated in these procedures.

The combination of the thermosensitive polymer, poly( $N$-isopropylacrylamide) (PNIPAM), having a phase transition feature according to temperature change against the LCST, with extractants for metal ions is one of the separation materials in the solid-liquid processes [1-6]. When the linear PNIPAM without crosslinking is added to the aqueous solution containing both the metal ion and the extractant, at a temperature higher than the LCST, the metal-extractant complex is entrapped into PNIPAM due to the hydrophobicity of the complex. Similar systems using copolymers of linear PNIPAM and ligands have also 
been reported [7-10]. Since these separation systems mainly focused on the concentration of metal ions in PNIPAM aggregates, the adsorption properties at higher temperatures than the LCST were investigated.

Thermal-swing adsorptions or extractions, where the amount of metal absorbed is controlled by the temperature, based on the phase transition of PNIPAM, have been recently developed. One of the simplest thermal-swing adsorption systems is crosslinked PNIPAM without any ligand for metal ions which is used for the adsorption of $\mathrm{Au}(\mathrm{III})$ [11]. The thermal-swing adsorption of $\mathrm{Au}(\mathrm{III})$ with PNIPAM was successfully achieved, where the adsorption amount of $\mathrm{Au}(\mathrm{III})$ at $50^{\circ} \mathrm{C}$ is much higher than that at $10^{\circ} \mathrm{C}$. PNIPAM was reported to possess a high selectivity for $\mathrm{Au}(\mathrm{III})$ against other precious and heavy metals, such as $\mathrm{Pt}(\mathrm{IV})$, $\mathrm{Pd}(\mathrm{II}), \mathrm{Cu}(\mathrm{II})$, and $\mathrm{Ni}(\mathrm{II})$, indicating that PNIPAM itself cannot be applied as an absorbent for these metals except for $\mathrm{Au}(\mathrm{III})$.

PNIPAM-based separation materials for the thermal-swing adsorption system are therefore generally combined with an extractant [12-15]. In our previous work, the crosslinked PNIPAM, copolymerized with an acidic extractant, were combined with single-walled carbon nanotubes, as a molecular heater. The photo-swing adsorption system was then investigated based on the heat generation by the carbon nanotubes with photo-irradiation [16]. In these previous papers, the extractant and NIPAM were copolymerized together with a crosslinker, and then the thermal- or photo-swing adsorption was carried out based on the phase transition of PNIPMA around the LCST. However, the largest disadvantage of the materials reported, especially when an acidic extractant is copolymerized with the crosslinked PNIPAM, is that the difference in the adsorption amount is small, and thus quantitative extraction-stripping of the metals is not achieved $[12,13,16]$. A thermal-swing adsorption system, having a large difference in the adsorption amount with phase transition of PNIPAM, is therefore still required, especially in the nuclear fuel cycle process, to reduce the amount of acid for stripping the metal ions.

The small difference in the adsorption amount is likely to be caused by insufficient changes in the volume and hydrophobicity of the composite gel. An extractant immobilizing in the linear PNIPAM is therefore expected to possess high potential as a separation material in the thermal-swing adsorption system. In the present work, the separation materials were prepared, by copolymerizing an extractant onto linear PNIPAM, in order to apply the thermal-swing adsorption. Two acidic extractant, namely acidic phosphoxy ethyl methacrylate (Phosmer-M, Figure 1) and acrylic acid, were used, and Eu(III) was used as a model metal ion in the nuclear fuel cycle process. Adsorption properties of Eu(III) at both lower and higher temperatures against the LCST was first investigated with copolymers having a different degree of crosslinking and a different extractant content. The thermal-swing adsorption of Eu(III) with repeated change of temperature was then conducted.<smiles>C=C(C)C(=O)OCCOP(=O)(O)O</smiles>

Figure 1. Chemical structure of Phosmer-M. 


\section{Experimental}

\subsection{Reagents}

Phosmer-M was supplied by Uni-Chemical Co., Ltd., Nara, Japan. All other organic and inorganic reagents were of analytical grade and were supplied by Wako Pure Chemical Industries, Ltd., Osaka, Japan. NIPAM was used after recrystallization from hexane.

\subsection{Synthesis of Phosmer-M/NIPAM and acrylic acid/NIPAM copolymers}

Phosmer-M/NIPAM and acrylic acid/NIPAM copolymers were synthesized as follows: the appropriate amount of NIPAM, Phosmer-M or acrylic acid, $N, N^{\prime}$-methylenebisacrylamide (BIS) and 2,2'-azobisisobutyronitrile (AIBN) were dissolved in $N, N$-dimethylformamide (DMF). The mixture was bubbled with nitrogen gas for $15-30 \mathrm{~min}$ to remove dissolved oxygen and was reacted at $60^{\circ} \mathrm{C}$ for $24 \mathrm{~h}$. The product was dissolved in DMF and then the DMF was removed by evaporation. The copolymer obtained was dissolved in a small amount of ethanol, and then was recrystallized using $n$-hexane. The final product was filtered and dried in vacuo at room temperature, and then was crushed. The precise compositions of the raw materials for Phosmer-M/NIPAM and acrylic acid/NIPAM are summarized in Tables 1 and 2, respectively.

Table 1. Composition of monomer, crosslinking agent, initiator, and solvent for the synthesis of Phosmer-M/NIPAM copolymer.

\begin{tabular}{cccccc}
\hline & $\begin{array}{c}\text { NIPAM } \\
(\mathrm{mmol})\end{array}$ & $\begin{array}{c}\text { Phosmer-M } \\
(\mathrm{mmol})\end{array}$ & $\begin{array}{c}\text { BIS } \\
(\mathrm{mmol})\end{array}$ & $\begin{array}{c}\text { AIBN } \\
(\mathrm{mmol})\end{array}$ & $\begin{array}{c}\text { DMF } \\
(\mathrm{mL})\end{array}$ \\
\hline$\# 1$ & 17.78 & 2.22 & - & 0.20 & 10 \\
$\# 2$ & 17.78 & 2.22 & 0.2 & 0.20 & 10 \\
$\# 3$ & 17.78 & 2.22 & 0.3 & 0.20 & 10 \\
$\# 4$ & 17.78 & 1.11 & - & 0.20 & 10 \\
$\# 5$ & 17.78 & 4.44 & - & 0.20 & 10 \\
\hline
\end{tabular}

Table 2. Composition of monomer, crosslinking agent, initiator, and solvent for the synthesis of acrylic acid/NIPAM copolymer.

\begin{tabular}{cccccc}
\hline & $\begin{array}{c}\text { NIPAM } \\
(\mathrm{mmol})\end{array}$ & $\begin{array}{c}\text { Acrylic acid } \\
(\mathrm{mmol})\end{array}$ & $\begin{array}{c}\text { BIS } \\
(\mathrm{mmol})\end{array}$ & $\begin{array}{c}\text { AIBN } \\
(\mathrm{mmol})\end{array}$ & $\begin{array}{c}\text { DMF } \\
(\mathrm{mL})\end{array}$ \\
\hline$\# 6$ & 20.0 & 20.0 & - & 0.834 & 20 \\
$\# 7$ & 20.0 & 20.0 & 0.2 & 0.834 & 20 \\
$\# 8$ & 20.0 & 20.0 & 0.8 & 0.834 & 20 \\
$\# 9$ & 10.0 & 30.0 & - & 0.834 & 20 \\
\hline
\end{tabular}

\subsection{Thermal-swing adsorption of Eu(III)}

The adsorption of $\mathrm{Eu}(\mathrm{III})$ was investigated using the Phosmer-M/NIPAM copolymer at $25^{\circ} \mathrm{C}$ and 50 ${ }^{\circ} \mathrm{C}$ and the acrylic acid/NIPAM copolymer at $5{ }^{\circ} \mathrm{C}$ and $50{ }^{\circ} \mathrm{C}$. The copolymer was firstly added to a solution of the appropriate concentration of $\mathrm{HCl}$ or $\mathrm{NaOH}$, and the mixture was shaken to completely dissolve the 
copolymer. $\mathrm{EuCl}_{3}$ solution was then added to the mixture. The resulting solution was shaken for more than $2 \mathrm{~h}$ in a water bath at each temperature. Detail of the experimental conditions are summarized in Table 3. Based on our preliminary experiments, adsorption was shown to achieve equilibrium after $2 \mathrm{~h}$ shaking. The mixture was then filtered with either a $5 \mathrm{C}$ filter paper or a $0.2 \mu \mathrm{m}$ membrane filter. The $\mathrm{pH}$ of the aqueous solution at the equilibrium state $\left(\mathrm{pH}_{\mathrm{eq}}\right)$ was measured with a $\mathrm{pH}$ meter (Horiba F-23), and the concentration of the Eu(III) was measured with an inductively coupled plasma atomic emission spectrometer (ICP-AES, Shimadzu ICPS-7000). The adsorption amount of Eu(III) was defined as:

$$
q=\frac{\left([\mathrm{Eu}(\mathrm{III})]_{\mathrm{fed}}-[\mathrm{Eu}(\mathrm{III})]\right) \cdot L}{w}
$$

where $[\mathrm{Eu}(\mathrm{III})]_{\text {feed }}$ and $[\mathrm{Eu}(\mathrm{III})]$ are the initial and equilibrium concentrations of $\mathrm{Eu}(\mathrm{III})(\mathrm{mmol} / \mathrm{L}), L$ is the volume of aqueous solution (L), and $w$ is the weight of the copolymer $(\mathrm{g})$.

Table 3. Detail of the experimental conditions for the thermal-swing adsorption.

\begin{tabular}{lcc}
\hline \multicolumn{1}{c}{ Copolymer } & Phosmer-M/NIPAM & acrylic acid/NIPAM \\
\hline Weight of copolymer $(\mathrm{mg})$ & 20.0 & 20.0 \\
Volume of $\mathrm{HCl} / \mathrm{NaOH}$ solution $(\mathrm{mL})$ & 9.5 & 3.0 \\
$\mathrm{EuCl}_{3}(\mathrm{~mL})$ & 0.5 & 1.0 \\
{$\left[\mathrm{Eu}^{3+}\right](\mathrm{mmol} / \mathrm{L})$} & 20.0 & 16.0 \\
\hline
\end{tabular}

\section{Results and Discussion}

\subsection{Effect of composition of the Phosmer-M/NIPAM copolymer on the adsorption amount of Eu(III)}

For all separation materials prepared, the phase transition of the copolymer was achieved by changing the temperature of the aqueous solution around the LCST; the copolymer was dissolved in an aqueous solution at $25^{\circ} \mathrm{C}$, while it was aggregated at $50^{\circ} \mathrm{C}$. Separation of the copolymers prepared in this work and the aqueous solution after adsorption at $25{ }^{\circ} \mathrm{C}$, however, could be achieved by filtration with either filter paper or a membrane filter. The effect of the content of the crosslinking agent on the adsorption amount of $\mathrm{Eu}(\mathrm{III})$ was firstly investigated using copolymers \#1 - \#3 by changing the temperature. Figure 2 shows the effect of $\mathrm{pH}$ on the adsorption amount of $\mathrm{Eu}(\mathrm{III})$. The adsorption amounts of $\mathrm{Eu}(\mathrm{III})$ in all systems increased with increasing $\mathrm{pH}$ values in the aqueous solution, just as for the conventional solvent extraction system. The adsorption amount of $\mathrm{Eu}(\mathrm{III})$ at $50^{\circ} \mathrm{C}$ increased over that at $25^{\circ} \mathrm{C}$ with the phase transition of the copolymer. When the content of the crosslinking agent is increased, the adsorption amounts of $\mathrm{Eu}(\mathrm{III})$ with copolymers $\# 1-\# 3$ at $25^{\circ} \mathrm{C}$ decreased, while those at $50^{\circ} \mathrm{C}$ increased with a decrease in the content of the crosslinking agent. The difference in the adsorption amount of $\mathrm{Eu}(\mathrm{III})$ was increased by decreasing the content of the crosslinking agent. This may be because the differences in the volume change and hydrophobicity of the copolymer caused by the phase transition are increased with a decrease in the content of the crosslinking agent. The copolymer without crosslinking shows a large difference in the adsorption amount of $\mathrm{Eu}(\mathrm{III})$ in the thermal-swing adsorption. The copolymer without crosslinking is thus used hereafter.

The effect of the Phosmer-M content in the copolymer was then investigated. Figure 3 shows the effect of $\mathrm{pH}$ on the adsorption amount of $\mathrm{Eu}(\mathrm{III})$ with the copolymers \#4 and \#5. Comparing the data for 
copolymer \#1 in Figure 1 with those of copolymers \#4 and \#5 in Figure 3, the adsorption amounts of $\mathrm{Eu}$ (III) at $25{ }^{\circ} \mathrm{C}$, were much increased, rather than those at $50{ }^{\circ} \mathrm{C}$, with an increase in the content of Phosmer-M. The difference in the adsorption amount against the phase transition of the PNIPAM therefore decreased with the content of Phosmer-M.

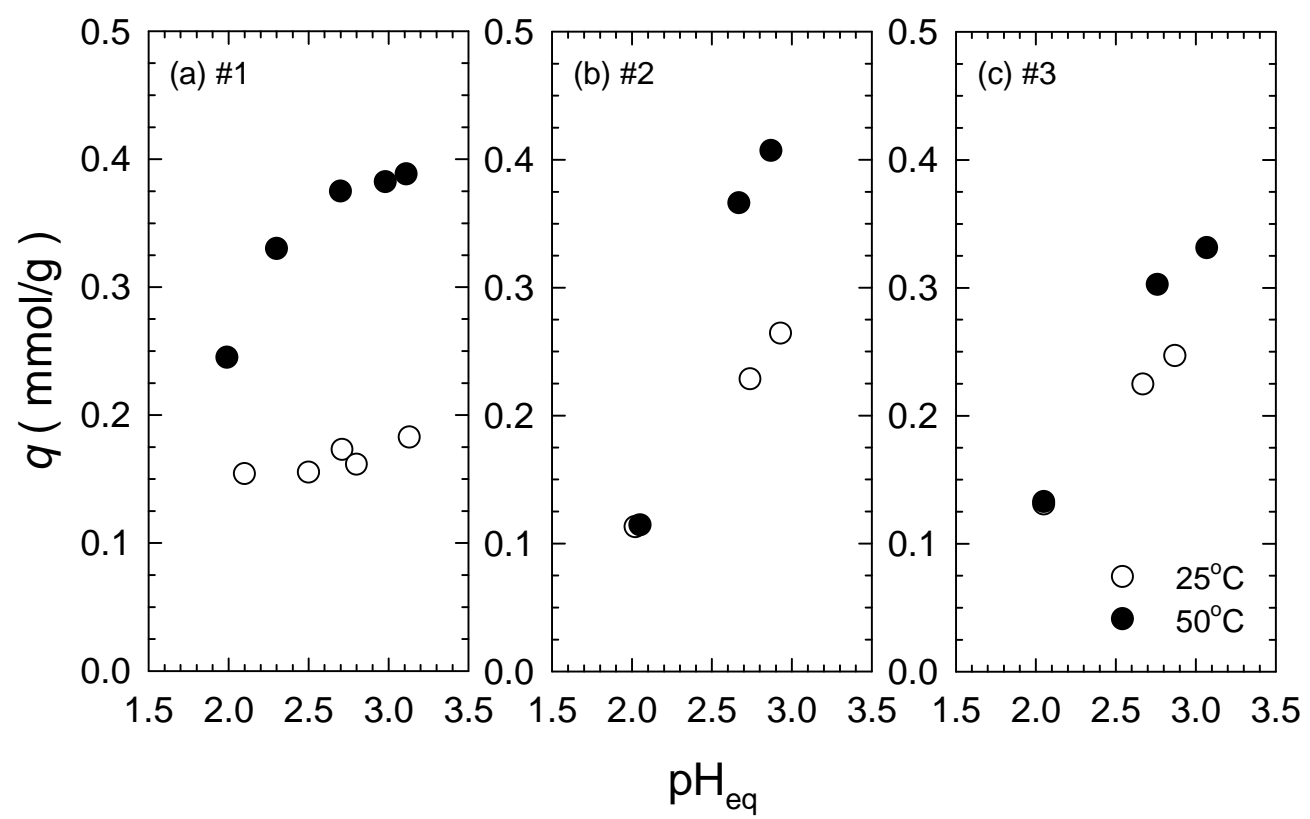

Figure 2. Effect of the equilibrium $\mathrm{pH}$ on the adsorption amount of $\mathrm{Eu}(\mathrm{III})$ with the Phosmer-M/NIPAM copolymers, (a) \#1, (b) \#2, and (c) \#3, at $25^{\circ} \mathrm{C}$ and $50^{\circ} \mathrm{C}$.

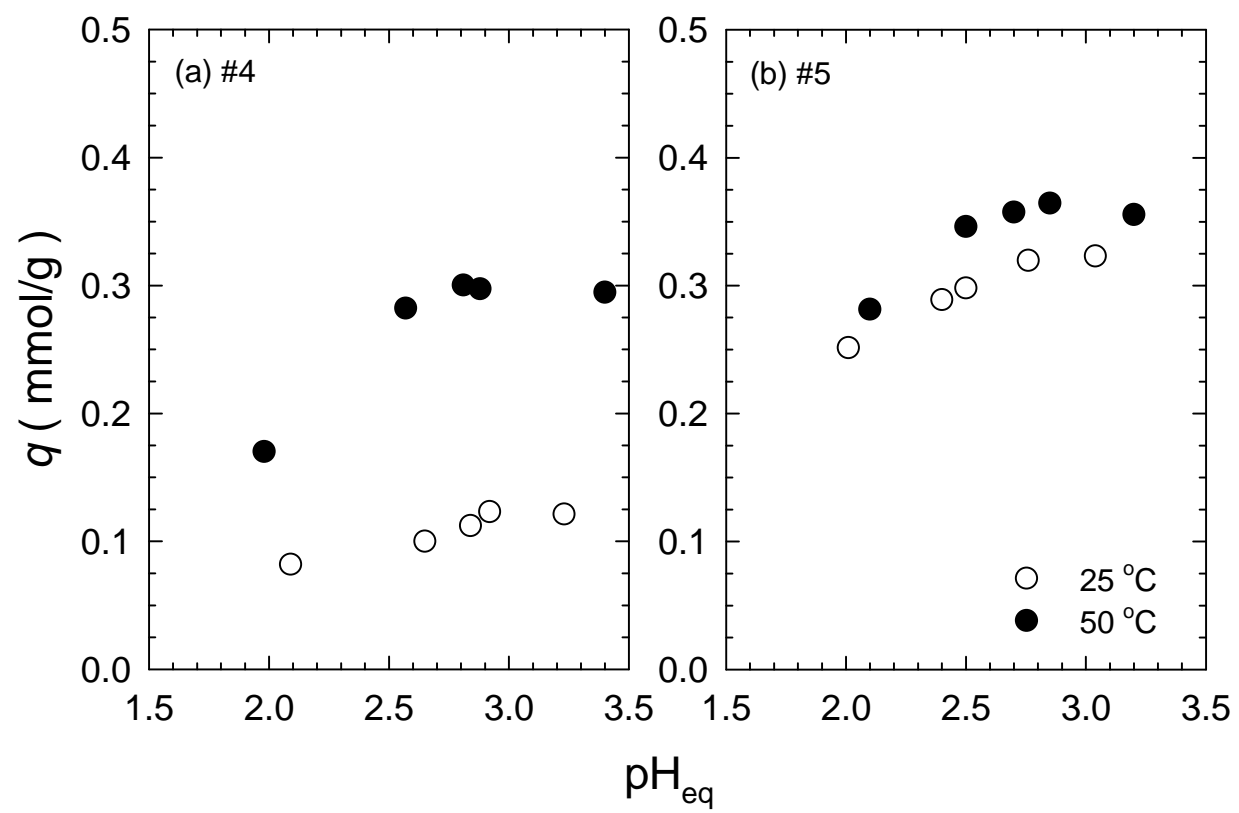

Figure 3. Effect of the equilibrium $\mathrm{pH}$ on the adsorption amount of $\mathrm{Eu}(\mathrm{III})$ with the Phosmer-M/NIPAM copolymers, (a) \#4 and (b) $\# 5$, at $25^{\circ} \mathrm{C}$ and $50^{\circ} \mathrm{C}$. 


\subsection{Thermal-swing adsorption of Eu(III) with the Phosmer-M/NIPAM copolymer}

Thermal-swing adsorption of $\mathrm{Eu}(\mathrm{III})$ with copolymers \#1 and \#4 was then carried out by changing the temperature between $25^{\circ} \mathrm{C}$ and $50^{\circ} \mathrm{C}$. Figure 4 shows the thermal-swing behavior of the adsorption amount of Eu(III) under repeated processing with the copolymers (\#1 and \#4). The phase transition of the PNIPMA is successively progressed to repeat the loading and release of $\mathrm{Eu}(\mathrm{III})$ via the temperature difference. However, the adsorption amount of $\mathrm{Eu}(\mathrm{III})$ at $25^{\circ} \mathrm{C}$ was slightly increased by the iteration, while that at $50^{\circ} \mathrm{C}$ was almost constant. Since the dissolution of the copolymer at temperatures lower than the LCST became worse during the iteration, the repeatability of the adsorption amount of Eu(III) has not been fully demonstrated.

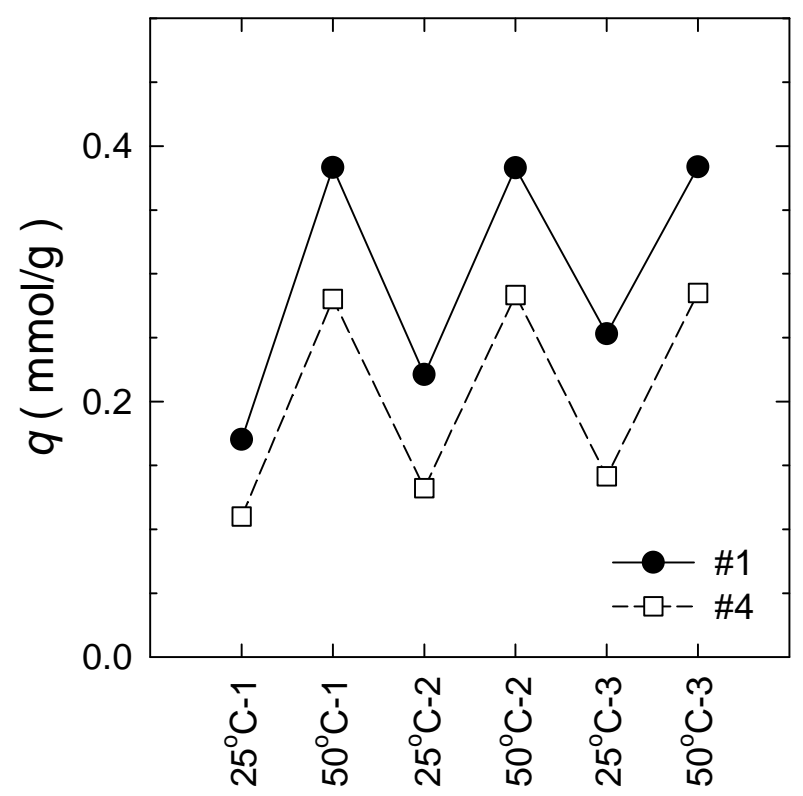

Figure 4. Effect of repeated processing on the adsorption amount of Eu(III) with the Phosmer-M/NIPAM copolymers (\#1 and \#4) at $\mathrm{pH}_{\mathrm{eq}, 25}=2.10(\# 1)$ and $\mathrm{pH}_{\mathrm{eq}, 25}=2.09$ (\#4).

\subsection{Effect of the composition of the acrylic acid/NIPAM copolymer on the adsorption amount of} Eu(III)

The adsorption properties of $\mathrm{Eu}(\mathrm{III})$ with the acrylic acid/NIPAM copolymer was also investigated at $5{ }^{\circ} \mathrm{C}$ and $50{ }^{\circ} \mathrm{C}$. Figure 5 shows the effect of $\mathrm{pH}$ on the adsorption amount of $\mathrm{Eu}(\mathrm{III})$ with copolymer \#6. In the case of the acrylic acid/NIPAM copolymer system, the adsorption amounts of Eu(III) were increased with an increase in the $\mathrm{pH}$ value in the aqueous solution, just as for Phosmer-M/NIPAM copolymer system. The $\mathrm{pH}$ range for the adsorption of $\mathrm{Eu}(\mathrm{III})$ was shifted to higher values rather than that in the case of the Phosmer-M/NIPAM copolymer system. This is due to the higher $\mathrm{p} K_{\mathrm{a}}$ value of the carboxyl group of the acrylic acid compared to the phosphate group of Phosmer-M. 


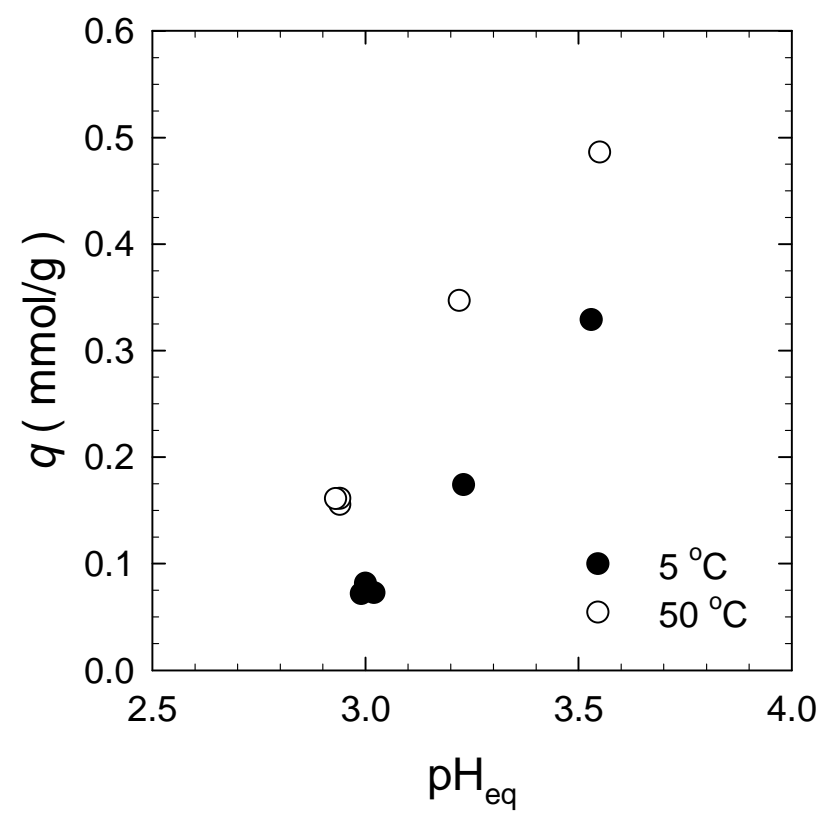

Figure 5 Effect of the equilibrium $\mathrm{pH}$ on the adsorption amount of $\mathrm{Eu}(\mathrm{III})$ with the acrylic acid/NIPAM copolymer $\# 6$ at $5^{\circ} \mathrm{C}$ and $50^{\circ} \mathrm{C}$.

\subsection{Thermal-swing adsorption of Eu(III) with the Acrylic acid/NIPAM copolymer}

The acrylic acid/NIPAM copolymer was then applied to the thermal-swing adsorption system. The copolymers having different degrees of crosslinking (\#6 - \#8) were firstly used for the thermal-swing adsorption, as shown in Figure 6. In the case of the acrylic acid/NIPAM copolymer, the difference in the adsorption ability of $\mathrm{Eu}(\mathrm{III})$ by the temperature change against the LCST is also increased by decreasing the content of the crosslinking agent, just as with the Phosmer-M/NIPAM copolymer.

Figure 7 shows the effect of the content of acrylic acid (\#6 and \#9) on the thermal-swing adsorption of $\mathrm{Eu}(\mathrm{III})$. A large difference in the adsorption amount at $5^{\circ} \mathrm{C}$ and $50^{\circ} \mathrm{C}$ is also obtained, even when the content of the acrylic acid is low during the copolymerization. In addition, the stable thermal-swing adsorption can be repeated with copolymer \#14. The linear PNIPAM immobilizing acidic extractant therefore possesses sufficient potential as a novel separation material for thermal-swing adsorption. 


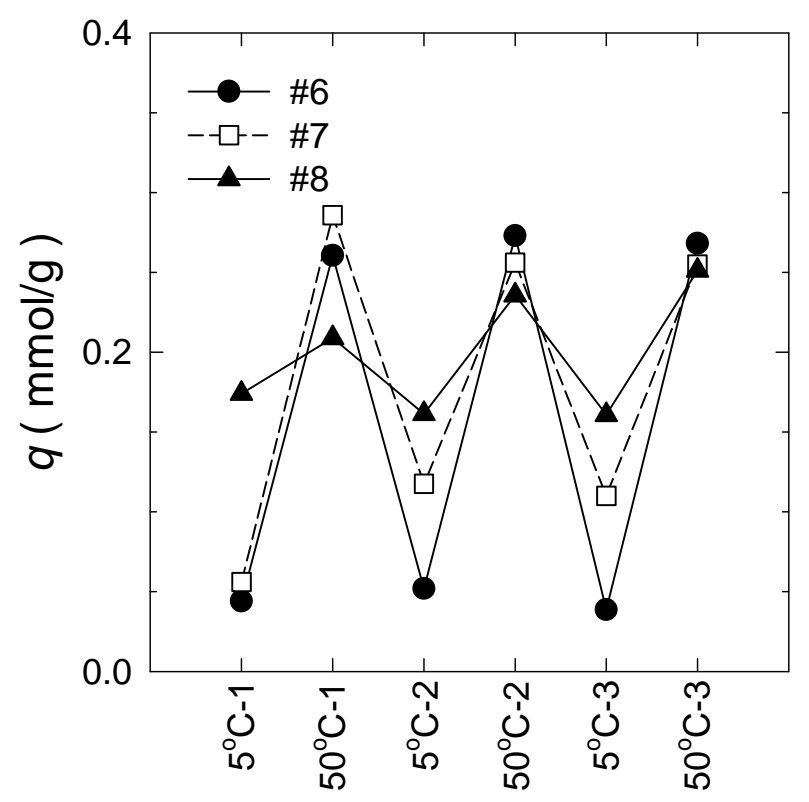

Figure 6. Effect of repeated processing on the adsorption amount of $\mathrm{Eu}(\mathrm{III})$ with the acrylic acid/NIPAM copolymers (\#6-\#8) at $\mathrm{pH}_{\mathrm{eq}, 5}=3.03(\# 6), \mathrm{pH}_{\mathrm{eq}, 5}=3.03(\# 7)$, and $\mathrm{pH}_{\mathrm{eq}, 5}=3.00$ (\#8).

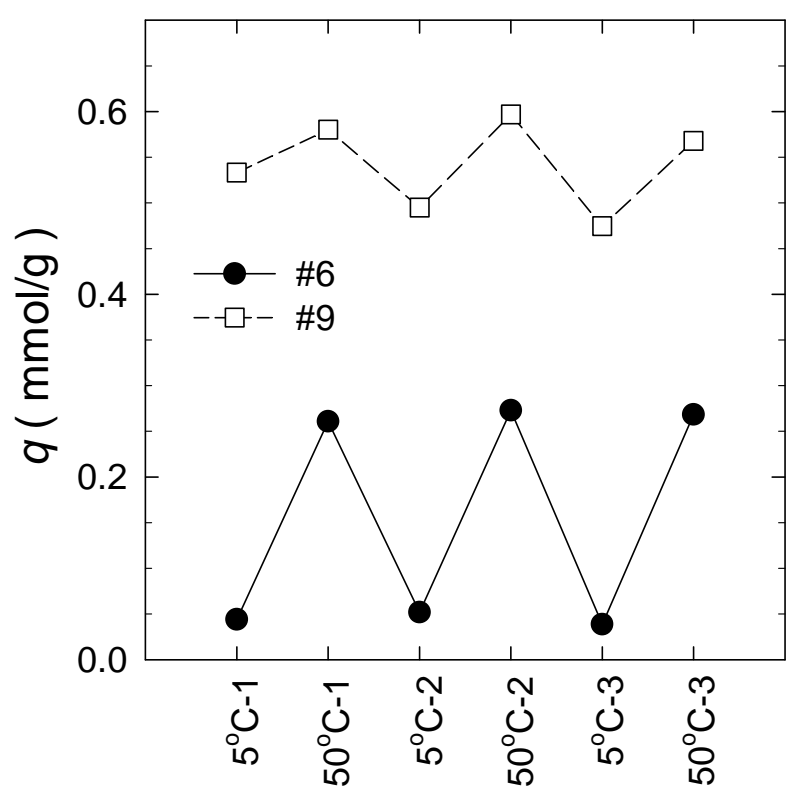

Figure 7. Effect of repeated processing on the adsorption amount of Eu(III) with the acrylic acid/NIPAM copolymers (\#6 and \#9) at $\mathrm{pH}_{\mathrm{eq}, 5}=3.03(\# 6)$ and $\mathrm{pH}_{\mathrm{eq}, 5}=2.94(\# 14)$. 


\section{Conclusion}

A novel thermal-swing adsorption system for Eu(III) with linear PNIPAM immobilizing acidic extractants, Phosmer-M or acrylic acid, has been investigated. The important features of the system can be summarized as follows.

(1) The difference in the adsorption amount of Eu(III) against the LCST is increased with a decrease in the content of crosslinking agent during the preparation of both Phosmer-M/PNIPAM and acrylic acid/PNIPAM copolymers, because the change in the volume and the hydrophobicity of the copolymer is increased.

(2) The difference in the adsorption amount of Eu(III) against the LCST is decreased on increasing the content of the extractant in the copolymer, because the adsorption amount at a lower temperature than the LCST is much increased than that at higher temperatures.

(3) These copolymers possess a sufficient loading capacity and release for $\mathrm{Eu}(\mathrm{III})$ under the repeated processes of the thermal-swing adsorption.

\section{References}

1) T. Saitoh, T. Ohyama, K. Takamura, T. Sakurai, T. Kaise, C. Matsubara, Anal. Sci., 13, 1-4 (1997).

2) T. Saitoh, T. Ohyama, T. Sakurai, T. Kaise, K. Takamura, Y. Suzuki, C. Matsubara, Talanta, 46, 541-550 (1998).

3) T. Saitoh, M. Haga, T. Sakurai, T. Kaise, C. Matsubara, Anal. Sci., 14, 929-933 (1998).

4) T. Saitoh, S. Ohkubo, C. Matsubara, Chem. Lett., 151-152 (1999).

5) H. Tokuyama, T. Iwama, Sep. Purif. Technol., 68, 417-421 (2009).

6) H. Tokuyama, J. Hisaeda, S. Nii, S. Sakohara, Sep. Purif. Technol., 71, 83-88 (2010).

7) K. Tagusari, N. Uehara, T. Shimizu, Bunseki Kagaku, 50, 257-262 (2001) (in Japanese).

8) T. Saitoh, F. Saitoh, M. Hiraide, Talanta, 61, 811-817 (2003).

9) K. Chayama, Y. Morita, S. Iwatsuki, J. Chromatogr. A, 1217, 6785-6790 (2010).

10) T. Saitoh, A. Arakawa, M. Hiraide, Bull. Chem. Soc. Jpn., 86, 438-444 (2013).

11) H. Tokuyama, A. Kanehara, React. Funct. Polym., 67, 136-143 (2007).

12) K. Takeshita, Y. Nakano, Solvent Extr. Ion Exch., 18, 375-386 (2000).

13) K. Takeshita, Y. Nakano, T. Matsumura, J. Nucl. Fuel Cycle Env., 7, 11-16 (2001).

14) K. Takeshita, M. Tanaka, Y. Nakano, Y. Seida, J. Chem. Eng. Jpn., 36, 1253-1258 (2003).

15) K. Takeshita, T. Matsuyama, Y. Nanako, Prog. Nucl. Energy, 50, 466-469 (2008).

16) S. Nishihama, K. Ohsawa, Y. Yamada, K. Yoshizuka, T. Fujigaya, N. Nakashima, React. Funct. Polym., 72, 142-147 (2012). 